\title{
El pluralismo cultural en América Latina y sus desafíos desde una perspectiva zubiriana: icómo acercarse al fenómeno religioso para responder a las inquietudes del ciudadano de hoy?
}

\section{Cultural pluralism in Latin America and its challenges. From a Zubirian perspective: How to approach the religious phenomenon to respond to the concerns of citizens today?}

0 pluralismo cultural na América Latina e seus desafios desde uma perspectiva Zubiriana: como abordar 0 fenómeno religioso para responder às inquietudes dos cidadãos de hoje?

Antonio Calderón ${ }^{1}$

Recibido: 21 de mayo de 2017 - Aceptado: 23 de julio de 2017

\begin{abstract}
Resumen
El estudio que se presenta aquí tiene por finalidad analizar la situación del pluralismo cultural en América Latina y sus desafíos. Para ello, se utiliza el método crítico-hermenéutico siguiendo el estudio en la literatura contemporánea y sus aportes a la nueva realidad (en el que la comprensión del pluralismo se hace necesaria), para acercarse a la fenomenología de la religión presente en la cultura y ver cómo ello gravita en el acontecer de la vida cotidiana. Para ello, se incluye la perspectiva de Xavier Zubiri, quien puede dar algunas pistas para comprender este fenómeno. Es importante considerar además, como desafíos ciertos puntos claves,
\end{abstract}

1 Boliviano, Licenciado en Educación y profesor de Religión por la Universidad Católica Silva Henríquez. Magíster en Ética Social y Desarrollo Humano por la Universidad Alberto Hurtado. Doctorando en filosofía por la Universidad Pontificia de Salamanca. Académico de la Universidad Católica del Maule. Contacto: acalderon@ucm.cl 
como la religación, el pensar religioso y la experiencia de lo religioso en la diversidad de realidades humanas de América Latina.

Palabras clave: pluralismo cultural - diálogo - religación - pensar religioso - experiencia de lo sagrado

\begin{abstract}
The purpose of this study is to analyze the situation of cultural pluralism in Latin America and its challenges. For this, it uses the critical-hermeneutic method following the study in contemporary literature and its contributions to the new reality (in which the understanding of pluralism becomes necessary), to approach the phenomenology of religion present in culture and see how it gravitates in the events of everyday life. For this, we include Xavier Zubiri's perspective, giving some clues to understand this phenomenon. It is also important to consider certain key points as challenges, such as religation, religious thinking and the experience of religion in diverse human realities in Latin America.
\end{abstract}

Keywords: Cultural pluralism - dialogue - religation - religious thinking experience of the sacred

\title{
Resumo
}

O estudo que se apresenta aqui tem por finalidade analisar a situação do pluralismo cultural na América Latina e seus desafios. Para isso, utiliza-se o método crítico-hermenêutico seguindo o estudo na literatura contemporânea e suas contribuições à nova realidade (onde a compreensão do pluralismo se faz necessária), para se aproximar a fenomenologia da religião presente na cultura e ver como isso gravita no acontecer da vida cotidiana. Para fazer isso, incluímos a perspectiva de Xavier Zubiri, quem pode dar algumas pistas para compreender este fenômeno. É importante considerar como desafios, certos pontos-chave, como a religação, o pensar religioso e a experiencia do religioso na diversidade de realidades humanas da América Latina.

Palavras-chave: pluralismo cultural - diálogo - religação - pensar religioso - experiência do sagrado

\section{Introducción}

En nuestra época, en América Latina, se constata una variedad de culturas y con ella sus costumbres y tradiciones religiosas. Esto obedece a razones muy de fondo; se vincula con las búsquedas con las que el ser humano de hoy intenta responder al misterio de su vida y su existencia. Una respuesta solo antropológica, histórica y científica 
pareciese no cumplir con las expectativas a esta realidad. Por otro lado, el problema de la educación religiosa en un ambiente plural, es un tema que aún debe ser debatido y asumido como un reto en las instituciones educativas. En ellas realmente no se ha planteado esa alternativa. Por ello, este estudio tiene la inquietud de profundizar, en un campo que se inicia hasta ahora y que debe ser orientado por las universidades formadoras de maestros. Al parecer, el pluralismo cultural debe contar con algún fundamento y puede ser considerado como un dato nuevo (signos de los tiempos), en el cual la reflexión creyente y no creyente entre en contacto con las demás fuentes y confesiones religiosas, para que mediante el diálogo auténtico, se fortalezcan las identidades y se promueva la interacción religiosa. Una perspectiva desde Zubiri podría darnos algunas pistas para llegar a este diálogo; ello supone mantener algunos temas claves básicos como la religación, el pensar religioso y la experiencia de lo sagrado en la diversidad de realidades humanas de América latina, y finalmente los desafíos de la enseñanza religiosa.

\section{La salida hacia el pluralismo: una experiencia en América Latina}

América Latina, como muchas otras partes del mundo, vive el proceso del pluralismo cultural religioso. Es una experiencia de gran desafío, que no se debe observar como una amenaza, sino como un reto que nos invita a una nueva inteligencia de construir ciudadanía en los diversos proyectos religiosos existentes. Y, como dice el Papa Francisco: "Salir de la propia comodidad y atreverse a llegar a todas las periferias que necesiten la luz" (Francisco 2013 20).

La situación contemporánea de las nuevas generaciones, específicamente en América Latina, es muy compleja, puesto que se debaten en una sociedad en transición y una dinámica bastante acelerada en varios ámbitos de la vida. "La novedad de estos cambios, a diferencia de los ocurridos en otras épocas, es que tienen un alcance global que, con diferencias y matices, afectan al mundo entero (...). Un factor determinante es la ciencia y la tecnología con su capacidad de manipular 
la vida misma y su capacidad de crear una red de comunicaciones al alcance mundial, (...) la historia se ha acelerado y los cambios mismos se vuelven vertiginosos" (Francisco 2013 20), por lo que se genera un fenómeno social diverso, del que emanan otros fenómenos, como por ejemplo lo religioso, un fundamento esencial de socialización y de humanización para las sociedades tradicionales y vinculadas a una confesión religiosa muy definida, con una institucionalidad marcada en el cristianismo. Sin embargo, hoy queda de manifiesto que la religión marcada desde una institucionalidad cristiana no tiene mayor relevancia e influencia. Esto obedece a la dinámica social que se vive hoy y, por tanto, aparecen en la realidad contemporánea - fruto de la globalización ${ }^{2}$ - una serie de distintas opciones y grupos religiosos que los jóvenes no comprenden, menos aún, cuando el proceso de secularización va incrementando su volumen ${ }^{3}$. ¿Será que hoy no existe diferencia entre lo que es religión y la opción creyente? ¿O que no existe una mirada más real sobre la cultura y la diversidad religiosa que esté de manifiesto en nuestros tiempos contemporáneos?

El problema al parecer es muy complejo, pero, por lo mismo, también desafiante, porque permite indagar para comprender el fenómeno desde sus raíces, y dar algunas pistas que ayuden a reflexionar acerca de soluciones que permitan una nueva configuración para una transformación pedagógica.

\section{Comprensión acerca del pluralismo}

El pluralismo tiene su vertiente y fundamentos en la diversidad, en la coexistencia de respeto entre las personas y los distintos grupos

\footnotetext{
2 Touraine indica que la "globalización" no designa únicamente la mundialización de los intercambios económicos: nos impone también una concepción de la vida social. Touraine, A. ¿Podremos vivir juntos? México: Ed. Fondo de Cultura Económica, 200, 34.

3 La Corporación Latinobarómetro, en su estudio "Las religiones en tiempos del Papa Francisco", indica el proceso de secularización que alcanza Chile, siendo con Uruguay uno de los países que se incrementó en los últimos tiempos, es decir, en el siglo XXI. Véase www.latinbarometro.org.
} 
sociales. Posee una exigencia de no discriminación a los demás: es decir, invita a la valoración y al respeto a aquello que es diferente a nosotros, sin olvidar la asimetría y relación del otro, o, como indica Levinas, acerca de la Alteridad ${ }^{4}$. Y, como las personas somos diferentes unas de otras en varios aspectos, de ahí que el pluralismo se plasme hoy como un principio de mayor aplicación en distintos ámbitos de la vida humana.

Por lo tanto, el ámbito de la pedagogía religiosa debe apostar por hacer referencia al reconocimiento, al respeto por las formas de vida y a las concepciones del mundo cultural religioso que existen en muchas sociedades de nuestra época; esto obedece a la apertura y a la conexión de las redes sociales, las cuales posibilitan una mirada diferente, es decir, un mundo globalizado. Ello implica entonces la capacidad de aceptar, valorar y respetar la existencia de otras formas de vida y otras maneras de comprender el mundo desde la cultura religiosa, que es parte del ser humano en sí mismo. Esto indica la imposibilidad de que sea una ley la que elimine el ser religioso de la persona; por lo tanto, un Estado no debe imposibilitar el cultivo cultural-religioso de sus miembros, ya que con ello estaría incumpliendo la libertad religiosa; por el contrario, su tarea debe ser velar y cuidar ese derecho. Por lo tanto, también desde el pluralismo religioso podemos comprender que se consagra la plena libertad religiosa y el trato igualitario de todas las confesiones religiosas existentes. Karl Lehmann sugiere que un auténtico pluralismo debe ser consciente de que se es parte de él, aunque no del todo, y plantea como exigencia de su práctica una predisposición para la autodisciplina y diálogo (Bergoglio 2015). En varias sociedades existe una clara separación entre el Estado y las iglesias, por ello se habla de Estado laico, es decir, un Estado neutro en cuestiones religiosas, que no asume una religión propia para permitir que cada ciudadano practique la que desee. Sin embargo, su obligación es entregar una mirada global sobre la cultura religiosa existente, porque como dijimos, el ser humano es religioso por esencia y su práctica

\footnotetext{
4 "La relación interpersonal que establezco con el otro, debo también establecerla
} con los otros hombres". Levinas, E. Ética e infinito. Madrid: Ed. Visor, 1998, 84. 
se realiza de modo social con otros, forjando así distintos grupos de opciones creyentes dentro de la interculturalidad 5 .

Ahora bien para que se genere un auténtico pluralismo social y religioso, se debe exigir un clima de responsabilidad, libertad y tolerancia, puesto que la clave de una sociedad pluralista es el respeto mutuo entre los diversos actores, que aceptan como base de su convivencia los Derechos Humanos y una constitución política asumida por la mayoría. Para el ejercicio sano del pluralismo necesitamos recurrir a un medio muy importante, que es la educación, pues ella será quien entregue los métodos y su enseñanza para un mejor avance del pluralismo en la cultura religiosa.

\section{La urgencia de la pedagogía frente al pluralismo}

El pluralismo no tiene un carácter exclusivo de los tiempos modernos y posmodernos, sino que ha estado presente a lo largo de la historia de la humanidad, en las civilizaciones antiguas como Egipto, Grecia, Roma, en la Edad Media, en la Revolución Industrial, y hoy en nuestra contemporaneidad se hace presente con la globalización, y de manera más perceptible con los medios de comunicación y con las TICs.

La característica del pluralismo de hoy tiene que ver con la migración de personas, porque con ésta viene también la cultura y todo lo que concierne a la vida social que cada persona trae consigo; con el encuentro de diferentes culturas, las personas están obligadas a permanecer juntas durante mucho tiempo, como plantea la $\mathrm{ONU}^{6}$.

\footnotetext{
5 "En la dimensión comportamental, se aspira a que la persona se encuentre cómoda en su relación con personas de diferentes culturas, con independencia de la distancia cultural que haya entre ellas. Se pretende lograr una adaptabilidad activa en el repertorio de los comportamientos con el fin de buscar el entendimiento y la tolerancia mutua". Véase Revista de Investigación Educativa, 27/1 (2009).

6 "El hecho de que cada persona y grupo humano sea diferente entre sí es el punto de unión que encontramos en medio de la diversidad. Lo que realmente une a todos los seres humanos es su capacidad de distinguirse de los demás, de establecer sus propias visiones de mundo, y es esta capacidad la que tienen en común todos los grupos y todas las personas". UNESCO Diversidad Cultural (2005): 25.
} 
Por otro lado, el fenómeno de la urbanización masificada genera una mirada distinta y ahí surge la pregunta de Touraine, si acaso podremos vivir juntos ${ }^{7}$, ya que se instala una alfabetización masiva y posteriormente por medio de las modernas TICs de masas, los individuos entran en contacto y diálogo con otras culturas y cosmovisiones diversas, sin dejar necesariamente el lugar geográfico en el que nacieron. Hasta aquí entendemos los efectos de este fenómeno, de ahí que el pluralismo sea transversal a todo lo que realiza hoy el ser humano.

Ahora bien, en la mirada de América Latina, la observación de este fenómeno de pluralidad también estuvo y está presente, tal como indica la $\mathrm{ONU}^{8}$. Hoy muchos países latinoamericanos tienen un sistema de democracia institucionalizada y ahí se vislumbra la tolerancia a nivel político, el respeto por la cultura y lo religioso con que se caracteriza el ser humano latinoamericano. De este modo, podemos asegurar que el pluralismo religioso debe ser una tarea a seguir desde la pedagogía.

En un brevísimo análisis, desde el punto de vista de las convicciones religiosas, observamos que la aparición del pluralismo ha supuesto en algunas sociedades latinoamericanas un incremento muy significativo de la indiferencia religiosa, tal como en el caso de Chile y Uruguay, donde el proceso de secularización se ha configurado con mayor rapidez. Ahora bien, por otro lado, en América Latina se genera una

\footnotetext{
7 "Frente a una sociedad mundializada, globalizada, que invade en todas partes la vida privada y pública de la mayor cantidad de personas (...) Miles y millones de individuos ven los mismos programas de televisión, toman las mismas bebidas, usan la misma ropa y hasta emplean, para comunicarse de un país a otro, el mismo idioma". Touraine, A. ¿Podremos vivir juntos? Op. Cit. 9.

8 De acuerdo con el análisis de la UNESCO, en América latina, esta diversidad siempre fue evidente, desde los primeros contactos entre los grupos de los pobladores originarios del continente y luego con el proceso de conquista española. Durante este periodo, la diversidad se manifestó por ejemplo a través de los llamados "sincretismos religiosos" entre la religión católica, las religiones indígenas y las que llegaron desde África con la esclavitud, en donde los santos cristianos eran al mismo tiempo representaciones de divinidades africanas e indígenas, ambas superpuestas y complementarias. Hoy en día la diversidad cultural de América Latina abarca además a nuevas culturas, con las cuales no se mantuvo contacto tradicionalmente, pero que han permeado ciertos aspectos, como la estética, la comida o la religión.
} 
migración de una religión a otra, por ejemplo, del catolicismo al protestantismo, y en estos últimos se plasma una ramificación sin límites. Sin embargo, se excluyen las creencias de los pueblos originarios, pese al reconocimiento de las Naciones Unidas, como manifiesta Irarrázaval $^{9}$. Esto es muy distinto del fenómeno de otros continentes, como el europeo, por ejemplo, en donde la indiferencia religiosa está marcada por el secularismo y el agnosticismo declarados; sin embargo, como decíamos, la migración pacífica pone en tela de juicio esta realidad: los migrantes de tradición musulmana establecen hoy subrepticiamente una tradición islámica en el continente europeo.

Esta dinámica pluralista, aplicada a la religión comparada en el caso latinoamericano, expresa que existen búsquedas religiosas en que se pertenece a una u otra confesión. Es decir, el pluralismo implica desafíos. Así, la comprensión del fenómeno religioso en situaciones democráticas depende de que se logre un grado de asentimiento suficiente de principios básicos de procedimiento para llevar los desafíos por caminos que sean más creativos. Para esa creatividad el mejor medio y la mejor herramienta es la educación, que nos debe proporcionar una ruta para este consenso de procedimiento, ya que están en juego los derechos y deberes de cultivar la religión como expresión de la cultura desde su aparición en este mundo y su trayecto histórico, como creyente y no creyente, en espacios públicos y privados. Es decir, cada Estado debe hacerse cargo del cultivo religioso en todos sus ámbitos, para aprender a vivir juntos, como indica Delors ${ }^{10}$.

El problema sucede cuando el pluralismo da paso a algo más afín al totalitarismo, cuando el Estado, siguiendo la tutela de las ideologías

\footnotetext{
9 En sus estudios, Irarrázaval indica que en 2007 las Naciones Unidas establecieron la Declaración de los Derechos de los pueblos Indígenas. Se les reconoce el derecho fundamental a ser iguales a los demás y también a ser diferentes. Esto último es crucial. Las peculiaridades culturales y religiosas no obstaculizan la equidad, sino todo lo contrario. Irarrázaval, D. Indagación cristiana en los márgenes. Santiago: Ed. Universidad Alberto Hurtado, 2013. 52.

10 "Se trata de vivir juntos conociendo mejor a los demás, su historia, sus tradiciones y su espiritualidad y, a partir de ahí, crear un espíritu nuevo que impulse la realización de proyectos comunes. Delors, J. La educación encierra un tesoro. Unesco, 1996. 16.
} 
y de los gobiernos de turno, quebranta la diversidad, matando así el espíritu de lo que entendemos como una sociedad libre, de respeto y tolerante. De esta manera, la exigencia de comprensión acerca del pluralismo en la cultura religiosa en nuestros tiempos, se hace necesaria y urgente.

\section{Acerca del pluralismo en la cultura religiosa}

El pluralismo religioso se ha ido gestando, con bastante fuerza, en los espacios de reflexión acerca de la diversidad de concepciones religiosas y opciones creyentes que existen en el mundo, otorgando una mayor conciencia ${ }^{11}$. De tal suerte, el pluralismo religioso se convierte en un hecho concreto que es imposible no tratar ${ }^{12}$.

Frente a cambios tan acelerados, el pluralismo religioso se presenta de modo transversal a creyentes y no creyentes, lo que genera una visión distinta de la realidad y, además, hace frente a una de las tareas más urgentes y decisivas. No existe una ignorancia ni una distancia indiferente frente a este fenómeno.

En el modo transversal, la tarea urgente no implica cambiar la realidad pluralista. Flores indica que la pluralidad es riqueza ${ }^{13}$ y se vincula con

\footnotetext{
11 "Dentro del contexto de pluralismo religioso que de hecho existe hoy y del que hay mayor conciencia que antes (...). Por lo tanto, (...) todas las religiones, que corresponden obviamente a las diferentes búsquedas religiosas de personas concretas a lo largo de la historia, son substancialmente buenas". Bentue, A. Jesucristo en el pluralismo religioso. Santiago, Chile: Ed. Universidad Alberto Hurtado, 2012. 172. 12 "... puesto que el principio de la pluralidad encuentra su fundamento primario en la sobreabundante riqueza y diversidad de las automanifestaciones de divinidad a la humanidad". Dupuis, J. Hacia una teología cristiana del pluralismo religioso. Santander: Ed. Sal Terrae, 2000. 568.

13 "La pluralidad no es escoria, es la riqueza y la pobreza de la finitud, las posibles esquirlas del conocimiento propio de un ser absoluto, las exploraciones de ser contingente, que nacen de la libertad y, por lo tanto, son necesariamente imprevisibles. W. Von Humboldt vio que subyacen, a la riqueza y diversidad de las lenguas, visiones de mundo, las cuales pueden ser consideradas como tantas aproximaciones de la humanidad a la verdad total". Flores, L. "Pluralidad en la teología". Rev. Sociedad Chilena de Teología, 1995 (27-29)
} 
el esfuerzo por un cambio de actitud personal frente a la misma. La diversidad de opciones creyentes en el mundo de hoy, de una u otra manera, tiene un rol muy relevante para la construcción de la sociedad humana. Un principio elemental es la paz como medio para alcanzar otras necesidades fundamentales del ser humano: por ello se exige un mayor protagonismo de las religiones en todo el mundo. Es cierto que, como manifiesta Habermas ${ }^{14}$, para alcanzar este compromiso se necesita utilizar el diálogo o convenciones como medio eficaz entre todos los miembros de la sociedad, y sobremanera, entre los que lideran de las diferentes religiones y opciones creyentes. Para ello, es necesario realizar una comprensión y visión desde las siguientes preguntas: ¿en qué consiste el hecho religioso?, ¿qué se entiende por religión? Para nuestro cometido, seguiremos a Zubiri en estas dos temáticas: el hecho religioso y qué es la religión.

\section{El hecho religioso según Zubiri}

Para Zubiri, el problema de cómo se distinguen los hechos religiosos, y en qué se distingue un hecho religioso de otro que no lo es, se relaciona con una pregunta esencial: ¿en qué consiste formal y constitutivamente lo religioso de un hecho en cuanto tal? ${ }^{15}$. Para comprender esta pregunta es preciso constatar que las religiones son hechos que existen en la sociedad, son hechos institucionalizados y sirven como presión social (esto lo indica también Durkheim ${ }^{16}$ ). Pero

\footnotetext{
14 Habermas indica que las actitudes basadas en sentimientos, que reaccionan a vulneraciones y que a su vez pueden expresarse en reproches, confesiones, condenas, forman ciertamente la base empírica de las obligaciones, pero no agotan un sentido semántico, las proposiciones normativas, en las que las obligaciones se manifiestan en el lenguaje, remiten más bien a un trasfondo de expectativas de comportamientos normativamente generalizados. Las normas regulan las relaciones de interacción, de manera que obligan de modo fundamentable a los actores que conviven a realizar ciertas acciones. Los deberes toman un carácter vinculante de la validez de normas de interacción que en lo que respecta a la pretensión que elevan se apoyan en buenas razones. Habermas, J. Aclaración de la ética del discurso. Madrid: Ed. Trotta, 2000. 151-152.

15 Zubiri, X. El problema filosófico de la historia de las religiones. Madrid: Ed Alianza, 1994. 15.

16 Durkheim, en el análisis que realiza sobre las representaciones religiosas, indica
} 
la institucionalidad, al ser el espíritu objetivo, no es la esencia propia del hecho religioso en tanto tal, porque el hecho religioso es anterior a lo social. Así, el mismo autor reconoce que lo religioso es justamente el hecho sagrado. Por su parte, Eliade comprende, asimismo, el hecho religioso desde un fenómeno cultural ${ }^{17}$.

Zubiri, por el contrario, piensa que la religación se relaciona con algo previo, algo dado en tanto potencia originaria, y por ello, se manifiesta o pertenece a la experiencia inicial o primigenia de todo ser humano. La religación no posee una característica modal, ni es una mera posibilidad; se vincula con aquello previo a cualquier posibilidad y condición de suyo. Por eso cabe indicar que la religación en Zubiri no es el mero trasunto idiomático de la visión heideggeriana, sino que surge de un concepto que, proviniendo de aquel, es claramente distinto. Zubiri realiza un avance frente a lo planteado por Heidegger y comienza por rescatar el orden trascendental para la causa del haber o de la realidad. La mundanidad y la religación pertenecen al orden del haber y, por tanto, no consisten en una mera modalidad o posibilidad. Son anteriores a toda posibilidad y condición de suyo.

Eso significa que para Zubiri las cosas son como "de suyo", no sólo se "actualizan" al ser humano en la aprehensión, sino más bien que se le "imponen" e imprimen en la aprehensión, como "última" instancia, como "posibilitante" y como "impelente". El ser humano se realiza en ultimidad, desde la posibilidad y "por" la impelencia imprimida; así, la realidad es actualizada en aprehensión. Este carácter de esencialidad de la realidad es lo que Zubiri llama el "poder de lo real"18,

que son representaciones colectivas y que expresan realidades colectivas. Durkheim, E. Las formas elementales de la vida religiosa. Madrid: Ed. Akal, 1992. 8.

17 Desde la perspectiva de la historia de las religiones, Eliade señala que la conciencia de un mundo real y significativo está íntimamente ligada al descubrimiento de lo sagrado. A través de la experiencia de lo sagrado ha podido captar el espíritu humano la diferencia entre lo que se manifiesta como real, fuerte y rico en significado. Eliade, M. Historia de las religiones. Barcelona: Ed. Paidós, 1999. 17.

18 Flores indica que lo real es lo individual. Eres tú, es ese hombre en su insustituibilidad, en su invisibilidad, es aquel individuo destacado y su trasfondo, es temporal, está cercado por lo irreal, etc. Flores, L. "Pluralidad en la teología". Op. Cit. 
que nos liga (une) a la realidad, nos "religa" (unifica). Es lo que Zubiri entiende por "religación"19.

Así, el poder de la realidad como último posibilitante e impelente (impresión) en Zubiri, tiene el sentido de "deidad". La deidad no significa divinidad, sino que es la propia realidad intramundana en cuanto es poderosa y religante (unificante). Ahora bien, esta dimensión del poder de la realidad está expresada de alguna manera en cada cultura ${ }^{20}$; sin embargo, existen culturas primigenias u originarias en las que el poder del ánima (animismo ${ }^{21}$ ) tiene el carácter de dominio en la cual se involucran todos sus aspectos ${ }^{22}$. De tal manera que el propio animismo es parte de este poder real, por ello no debe efectuarse una mirada diferente o con carácter independiente ${ }^{23}$, porque el poder está igualmente en ella.

19 Zubiri aclara que la religación es la dimensión radical de mi realidad sustantiva en cuanto personal, esto es, en cuanto construye su Yo, su ser. De ahí que, al tener experiencia de esta construcción, se esta experienciando el poder de lo real y, por tanto, el poder de la deidad (aquí experiencia es prueba física de realidad); por consiguiente, es una experiencia que perfila no solamente la idea de Dios, sino su realidad absolutamente absoluta, en cuanto manifestada en forma de deidad. $Y$ esta experiencia es la experiencia radical de la persona humana en cuanto construye la figura de su Yo". Zubiri, X. El hombre y Dios. Madrid: Ed. Alianza, 2003. 156.

20 El fenómeno religioso es una dimensión antropológica universal, presente en la vida humana desde sus orígenes más primitivos, si bien tal hecho puede recibir interpretaciones diversas en cuanto a su significado. Bentué, A. Dios y dioses. Historia religiosa del hombre. Santiago, Chile: Ed. Universidad Católica de Chile, 2009. 33.

21 Samuel aclara que ser animista es creer en la existencia y en la realidad de un mundo invisible. El hombre no se limita a su cuerpo. La Tierra, los astros, los animales, los mismos vegetales pertenecen a un cierto orden del mundo que vincula entre si todos los elementos del cosmos. Samuel, A. Para comprender las religiones en nuestro tiempo. España: Ed. Verbo Divino, 1989. 18.

22 Zambrano indica que era necesaria esta primera forma en que la realidad —ambigua, escondida, inagotable - se hace presente. Zambrano, M. El hombre y lo divino. México: Fondo de Cultura Económica, 2005. 60.

23 El "poder" es un carácter propio, independientemente de las interpretaciones que aun dentro de esas mentalidades pueda recibir. Por ejemplo, la poderosidad no significa espíritu, o "ánima" o algo semejante. La idea de poder no es sinónima de "animación". Todo lo contrario. El propio animismo presupone la idea de poder, y es solo una interpretación suya, la interpretación animista del poder. Zubiri, X. Sobre Esencia. Madrid: Alianza Editorial, 1997. 510. 
Ahora bien, el poder de lo real se plasma en los hechos históricos de las religiones o, como dice Zambrano, es la primera forma de develación ${ }^{24}$. Por tanto, para Zubiri, las poderosidades reales se encuentran en las antiguas religiones en forma de dioses, que dominan las cosas reales ${ }^{25}$. El poder adquiere una diversidad de formas para mostrarse y, por ello, tiene varias modalidades, tratándose de un poder manifestante que compete a la realidad de lo que son, y de allí que el filósofo enumere en una lista sus manifestaciones ${ }^{26}$. Así, los dioses (Zambrano 2005 50) generan campos vitales en los que su influencia despierta una actividad o una actitud humana. Allí se establece el politeísmo, en el que las características que menciona Zubiri calzan acertadamente. Sin embargo, también estas manifestaciones de la deidad se vislumbran en culturas distintas de las primitivas, como la de los de griegos y romanos posteriormente. Zubiri plantea que este poder real tiene su carácter formal de deidad ${ }^{27}$ también en ellos.

\footnotetext{
24 "Entre el hombre y la realidad que le rodea, aun de la misma realidad que es su vida, se han interpuesto siempre imágenes. Sagradas al principio, se han convertido más tarde en simples representaciones, abriendo así la posibilidad a todo este mundo figurativo en que, de una parte, se representan las cosas visibles $y$, de otra, se da forma al contenido de las creencias y todo aquello que gime en el interior del alma humana". Zambrano, M. El hombre y lo divino. Op. Cit. 60.

25 "En las religiones más o menos antiguas en forma de dioses. Pues bien, dejando de lado el que sean dioses y el que pertenezcan a religiones, atengámonos solamente a la forma en que esas cosas reales, que son los dioses, dominan sobre las cosas. Esos modos de dominancia son justo sus poderosidades, sus poderes reales". Zubiri, X. El hombre y Dios. Op. Cit. 157.

26 "1) Trátase de un poder que se nos presenta ante todo como el poder de lo alto, el "altísimo"; 2) es además un poder del tiempo como mensura viva de la realidad; 3) es un poder de separación de formas; 4) es un poder de germinación de la realidad; 5) es un poder de organización, sobre todo de la vida; 6) es un poder del futuro; 7) es un poder no sólo de la realidad material sino también intelectual del hombre; 8) es el poder de la intimidad personal que vincula a los hombres en familias, tribus y naciones; 9) es el poder que lo llena todo lo mismo en el espacio que en el tiempo; 10 ) es el poder que se cierne sobre la vida y sobre la muerte; 11) es el poder que dirige la vida social; 12) es el poder que se llama destino; 13) es el poder que rige la justeza y la estructura cosmomoral del universo; 14) es el poder sacralizante; 15) es el poder perdurante". Ibíd. 89-90.

27 "Los griegos rozaron con algo esencial que no ha ocupado ningún lugar propio en la filosofía: el carácter de las cosas que ni son dioses ni son divinas, pero sin embargo tienen algo de este carácter: son formalmente deidad". Ibíd. 156.
} 
De manera que todo este constructo del poder de lo real, de la deidad, es dado en la historia del ser humano. Por lo tanto, el poder de lo real también hoy provoca que el ser humano esté lanzado a la búsqueda de un sentido fundante por medio del apoderamiento en la religión.

\section{La religión como experiencia desde Zubiri}

Nuestra tarea es acercarnos aquí al modo en que entiende Zubiri la religión, porque el tema en sí mismo sería inabordable. Ahora bien, toda esta experiencia de la religación se concretiza de modo individual y, además, se hace cargo de la historia con carácter social. Esa concreción está orientada hacia la religión, en la que el poder de lo real se hace parte del ser humano, es decir, es un apoderamiento del poder de lo real en la religación, de tal suerte que la religión no tiene un carácter actitudinal ante lo sagrado, porque: "Todo lo religioso es ciertamente sagrado; pero es sagrado por ser religioso, no es religioso por ser sagrado" ${ }^{28}$. De tal manera, la religión se concretiza de modo individual en la historia y en lo social como lo sagrado y, por tanto, su comprensión fenomenológica obedece a las disciplinas de la antropología, la sociología y la historia de las religiones, las cuales intentan dar respuestas al dinamismo de la experiencia religiosa de Dios en el ser humano y su mundo.

La experiencia religiosa no se remite sólo a la historia de las religiones. Puesto que todo ser humano, pese a no considerar su opción creyente a ninguna religión histórica, también posee algo de una cierta experiencia religiosa, e incluso experiencia de su misma constitución finita, como indica Sahagun ${ }^{29}$. Esto es porque "los dioses crean una especie de campos vitales donde su influencia hace posible una actividad o una actitud humana" (Zambrano 2005 59), por lo cual, para

28 Zubiri, X. El hombre y Dios. Op. Cit. 380.

29 "En el fondo, indica Sahagun que está siempre la experiencia la experiencia de finitud razonada por el hombre, así como la necesidad de infinitud. Se trata, por tanto, de una relación de dependencia basada en la misma constitución del ser humano". Sahagun, J. Dios, horizonte del hombre. Madrid: BAC, 1994. 23. 
Zubiri, toda experiencia humana tiene un sentido y una experiencia religiosa propia.

Aunque la experiencia religiosa individual sea, a manera suya, particular, la experiencia de lo absoluto es una experiencia a partir de otro, por ello tiene connotación social. Zubiri rescata este hecho, indicando que "realmente, la experiencia no es atributo del hombre, sino de los hombres en su concreción" (Zubiri 2003 335). Así, la experiencia de Dios, además de individual y social, es histórica. Zubiri define la historia como una experiencia de la realidad y, por tanto, también como experiencia de Dios. Por eso la historia de las religiones dentro de la historia humana es "una dimensión" muy importante: en ella se da "una perspectiva" de toda la historia humana, que es la experiencia del fundamento, del poder de lo real. Toda la historia humana es historia de las religiones. De ahí que la historia ${ }^{30}$ de las religiones no solo sea una línea cronológica o un lugar preciso de las diversas divinidades, sino el proceso de concreción de la experiencia teologal a lo largo de la historia de la humanidad. Al ser una experiencia en la historia, las religiones tienen un camino progresivo, que hace inacabable la experiencia teologal de la humanidad de forma individual, social e histórica, la cual acerca a la verdad última del poder de lo real, de Dios.

Por tanto, al analizar la historia de las religiones nos encontramos con algunos elementos fundamentales en los que el ser humano ha logrado sustantivar las manifestaciones del poder de lo real. Donde el hombre es el enigma de la inquietud y la voz de la conciencia, inherente al hecho mismo de la religación, lo que hace que el ser humano se lance hacia el fundamento, poniéndose en "marcha". El hombre ha de marchar desde la deidad en busca del fundamento. Para ello puede seguir distintas vías: una primera es la del fundamento múltiple, que conduce al verdadero politeísmo; la segunda es la vía de la inmanencia

30 "Ha sido Hegel quien precisó antes que la pregunta, la respuesta. Pues descubrió la historia como una vicisitud necesaria, inexorable del espíritu (...) la realidad no podía ser la naturaleza creada y hecha de una vez para siempre, sino esa otra de la que el hombre es portador y actor de la historia (...) y que sea ella, la historia, la depositaria de sentido". Zambrano, M. El hombre y lo divino. Op. Cit. 14. 
o inmersión, que desemboca en el panteísmo; y la tercera es la vía de la trascendencia, que conduce al monoteísmo.

Estos tres caminos son rutas en la que el hombre, a lo largo de la historia de la humanidad ha recorrido, con el único sentido de encontrar su fundamento. Por medio de ellas — cualquiera de ellas — se posibilita un acercamiento y acceso al ser divino. Estas vías aún se encuentran vigentes, incluso en la globalización, donde la vida personal y social tiene otros rumbos, que se desmarcan de la realidad tradicional en la que el sujeto estaba bajo la suprema potestad de la sociedad. Hoy no es así, el sujeto es actor autónomo y la sociedad es sólo un momento más de esa historia, como indica Rojas (1995 94), porque las relaciones con el otro están fracturadas.

\section{La religación como un aporte al pluralismo del fenómeno religioso cultural}

Ahora bien, la sugerencia de Zubiri es muy relevante, porque la comprensión de la religación es básica para comprender una experiencia del ser absoluto. Todos estamos religados, porque nuestra propia realidad es resultado de la donación entre seres humanos y, por ende, a la divinidad. En este nivel, evidentemente la experiencia de Dios es común a teístas, agnósticos y ateos, por lo que podemos denominarla el "nivel de la religación". Es en este ámbito donde se debe elaborar un trabajo iniciático de la diversidad y el pluralismo en la educación religiosa.

El pluralismo religioso es un acontecimiento, es una experiencia histórica que no se puede minimizar. Sus planteamientos deberían aportar mucho a la teología, a la filosofía y a la educación religiosa, puesto que exigen ver y percibir la situación del ser humano desde otra perspectiva, contraria a la que tradicionalmente se ha considerado. Vigil (2004 7) llama al investigador a asumir sin miedos el pluralismo religioso: "La pluralidad de las religiones, en un mundo en trance de unificación tan acelerada como jamás había conocido la historia humana, nos coloca a todos, creyentes y no creyentes, ante una de las tareas más urgentes y decisivas". 
Hoy se necesita un mayor esfuerzo por cambiar la actitud personal frente a este hecho. La diversidad de creencias u opciones creyentes en el mundo de hoy, sea de una u otra forma, tiene un rol muy relevante para la construcción de la sociedad humana. Uno de los valores que se debe priorizar constantemente es el de la paz, como herramienta para lograr satifacer las necesidades básicas del ser humano, lo que exige un compromiso real de los diversos grupos religiosos en todo el mundo. Para alcanzar este compromiso, se necesita un diálogo de todos los miembros de la sociedad y, de manera especial, de los líderes de las diferentes religiones. Ahora bien, el diálogo de las religiones entre sí debe ser de mucho respeto, por ello es necesario que la educación sea la mediadora, entregando herramientas para investigar los fundamentos de las religiones, cómo se originan y cuál es su sentido. Por lo tanto, la religación es más real en el encuentro con quien tiene una práctica creyente distinta: se hace más cercana la comprensión de la religión.

\section{Conclusión}

Aunque hoy muchos piensan que el fenómeno religioso no debe estar en la vida del ser humano y que la religión debe ser erradicada, esto no es posible. Al contrario, el pluralismo, el fenómeno religioso y la diversidad hacen que emerja con mayor relevancia una oportunidad para los investigadores, científicos sociales y de la religión de generar modelos teóricos de interpretación de lo que es el fenómeno religioso y sus búsquedas simples de espiritualidad, de manera que respondan a las características de nuestros tiempos, en los que la pluralidad y la autonomía muestran un sentir más cercano al sentido de la vida, no necesariamente anclado en lo sagrado.

Las carencias espirituales y personales no satisfechas por las religiones oficiales o institucionales, como sería el caso de la rigidez y entumecimiento de las formas institucionales, el no sentirse integrado o considerado como persona, el no tomar lo religioso en su plenitud de experiencia vivida, el no dar la suficiente acogida a lo afectivo, lo emocional, etc., también pueden interpretarse como factores causales de esa pluralidad de formas religiosas. 
A esto se suma la relativización total de los sistemas de valores y esquemas de interpretación, socavando el conocimiento, la aceptación de todo lo dado por supuesto hasta ese momento, lo cual conlleva a un proceso de elección personal e individual entre múltiples alternativas, proceso que lleva a la pluralidad religiosa, pues cada uno escoge su parte de porción simbólica y la combina con otras provenientes de otros caudales de sentido.

Conscientes de esta problemática que aqueja a las sociedades latinoamericanas, ¿cómo aprovechar entonces este momento del pluralismo y del fenómeno religioso para elaborar un acercamiento a una cultura religiosa más amplia, que posibilite que el ciudadano esté bien informado y consciente de que aquello en lo que va creer no sea una estafa o un engaño? La finalidad es desentrañar y descubrir cómo afecta esta realidad de pluralismo y diversidad al tema de la religación que, ciertamente, implica reconocer cómo estamos en la realidad y cómo estamos afectos a ella; no es la realidad que buscamos, sino que ella es en sí misma tal cual es y el ser humano se va empoderando de ella. Finalmente, la tarea es generar una mirada global de los cambios en que nos encontramos hoy más que en otros tiempos: es analizar la complejidad del sentido de vida que tiene el ser humano de hoy.

\section{Bibliografía}

Bentué, Antonio. Jesucristo en el pluralismo religioso. Santiago, Chile; Ed. Universidad Alberto Hurtado, 2012.

Bentué, Antonio. Dios y dioses. Santiago, Chile: Ed. Universidad Católica de Chile, 2009.

Bergoglio, J. M. SJ. "El Pluralismo Teológico". Humanitas 79 (2015).

Delors, Jacques. La educación encierra un tesoro. Ed. Unesco, 1997.

Dupuis, Jacques. Hacia una teología cristiana del pluralismo religioso. Santander: Ed. Sal Terrae, 2000.

Durkheim, Emile. Las formas elementales de la vida religiosa. Madrid: Ed. Akal, 1992.

Eliade, Mircea. Historia de las religiones. Barcelona: Ed. Paidós, 1999. 
Flores, L. "Pluralidad en la teología". Rev. Sociedad Chilena de Teología, 1995 (27-29).

Francisco. "Exhortación Apostólica". Evangelii Gaudium. Santiago de Chile: Ed. Salesianos Impresores, 2013.

Habermas, Jürgen. Aclaración de la ética del discurso. Madrid: Ed. Trotta, 2000. Irarrázaval, Diego. Indagación cristiana en los márgenes. Santiago, Chile: Ed. Universidad Alberto Hurtado, 2013.

Levinas, Emmanuel. Ética e infinito. Madrid: Visor, 1998.

Rojas, Enrique. El hombre light. Santiago, Chile: Temas de Hoy, 1995.

Sahagun, Lucas. Dios, horizonte del hombre. Madrid: BAC, 1994.

Samuel, Antonio. Para comprender las religiones en nuestro tiempo. España: Verbo Divino, 1989.

Touraine, Alain. ¿Podremos vivir juntos? México: Fondo de la Cultura Económica, 2006.

Vigil, José María. Teología del Pluralismo Religioso. Ecuador, Quito: Abya Yala, 2004.

Zambrano, María. El hombre y lo divino. México: Fondo de Cultura Económica, 2005.

Zubiri, Xavier. Sobre Esencia. Madrid: Alianza Editorial, 1997.

Zubiri, Xavier. El problema filosófico de la historia de las religiones. Madrid: Alianza Editorial, 1994.

Zubiri, Xavier. El hombre y Dios. Madrid: Alianza Editorial, 2003.

\section{Revistas:}

Documento de Aparecida. N 34 Ed., CELAM. 2007

Revista de Investigación educativa Murcia 27/1 (2009). Revista UNESCO Diversidad cultural, Santiago de Chile (2005).

Revista Sociedad Chilena de Teología Pluralidad en la teología. Ed. San Pablo, Santiago de Chile (1995).

\section{Páginas web:}

http://www.latinobarometro.org 